\title{
VISUAL-SPATIAL SKILLS AND MATHEMATICS CONTENT CONCEPTUALISATION FOR PRE-SERVICE TEACHERS
}

\author{
Chipo Makamure ${ }^{1^{*}}$, Zingiswa M. Jojo ${ }^{2}$ \\ ${ }^{1}$ Department of Science and Technology Education, University of South Africa, South Africa \\ ${ }^{2}$ Department of Mathematics Education, University of South Africa, South Africa \\ *Corresponding Author: makamburec@gmail.com
}

\begin{tabular}{l}
\hline \hline Article Info \\
Article history: \\
Received: September 09, \\
2021 \\
Accepted: October 11, 2021 \\
Published: November 20, \\
2021
\end{tabular}

\section{Keywords:}

Coordinate geometry

Mathematics content

knowledge

Pre-service teachers

Spatial orientation skills

Visual-spatial skills

\begin{abstract}
Empirical evidence in literature identified significant association between spatial ability and educational performance particularly in science, technology, engineering and mathematics (STEM). The purpose of this study was to explore pre-service teachers' spatial skills in solving mathematics problems, in the context of coordinate geometry. It is envisaged that spatial skills allow for the perception of visual information and, therefore, spatial cognition has been considered as a key skill in teaching mathematics. However, literature asserts that teachers are ill prepared to teach mathematics, hence there is limited use and misuse of spatial skills in teaching the subject. This study, therefore, examines the spatial orientation of pre-service teachers in teaching coordinate geometry. This is a mixed methods study in which pre-service teachers answered a coordinate geometry test to explore their content knowledge and their ability to interpret, analyse and apply visual spatial models to solve mathematical problems in coordinate geometry. The study established that the spatial orientation skills of pre-service teachers determine their performance in mathematics, especially coordinate
\end{abstract} geometry.

\begin{tabular}{l} 
KETERAMPILAN VISUA \\
\hline Kata Kunci: \\
Mengkoordinasikan geometri \\
Pengetahuan konten \\
matematika \\
Calon Guru \\
Keterampilan orientasi spasial \\
Keterampilan visual-spasial
\end{tabular}

\section{UAL-SPASIAL DAN KONSEPTUALISASI KONTEN MATEMATIKA CALON GURU}

\begin{tabular}{l} 
ABSTRAK \\
\hline Tujuan dari penelitian ini adalah untuk mengeksplorasi \\
keterampilan spasial guru pra-layanan dalam memecahkan masalah \\
matematika, dalam konteks geometri koordinat.Hal ini \\
dibayangkan bahwa keterampilan spasial memungkinkan untuk \\
persepsi informasi visual dan oleh karena itu, kognisi spasial telah \\
dianggap sebagai keterampilan kunci dalam mengajar \\
matematika.Namun, literatur menegaskan bahwa guru tidak siap \\
untuk mengajar matematika, maka ada penggunaan terbatas dan \\
penyalahgunaan keterampilan spasial dalam mengajar subjek.Oleh \\
karena itu, penelitian ini meneliti orientasi spasial guru pra-layanan \\
dalam mengajar geometri koordinat.Ini adalah studi metode \\
campuran di mana guru pra-layanan menjawab tes geometri \\
koordinat untuk mengeksplorasi pengetahuan konten mereka dan \\
kemampuan mereka untuk menafsirkan, menganalisis dan \\
menerapkan model spasial visual untuk memecahkan masalah \\
matematika dalam geometri koordinat.Studi ini menetapkan bahwa \\
keterampilan orientasi spasial guru pra-layanan menentukan kinerja \\
mereka dalam matematika, mengkoordinasikan geometri pada \\
khususnya.
\end{tabular}




\section{INTRODUCTION}

Previous studies, have demonstrated a strong relationship between spatial skills and mathematical learning and achievement [1-3]. Spatial thinking can be considered as an amalgam of cognitive skills comprising knowledge of concepts of space, using tools of representation, and applying processes of reasoning [4]. Spatial thinking therefore, allows individuals to use space to model the world (real and theoretical), structure problems, find answers, and express and communicate solutions [4]. The incorporation of concepts of space hence makes spatial thinking distinctive from other types of thinking [4]. According to [4], tools of representation such as graphs, sketches, diagrams, images, and models enable and support spatial thinking. These tools are used in various forms such as mental images, visual media, auditory, and/or kinesthetic forms to identify, describe, explain, and communicate information about objects and their associated spatial characteristics [4]. The ability to use these tools to facilitate spatial thinking therefore reflects spatial skills/literacy in pre-service teachers. Research in spatial ability has been substantial and has seen a resurgence since it has been linked with educational performance, especially in STEM subjects [5]. This study could therefore prove to be beneficial in the education arena since it focuses on uncovering the factor structure of spatial ability in mathematics, and recommending interventions to enhance spatial thinking among mathematics pre-service teachers.

Abrahamson et al. also suggest that knowing about space includes the nature of spaces and coordinate systems like the Cartesian and polar coordinates [6]. Further allude to representing space as looking at the relationships of different views of an object, readability of graphs/maps, and the effects of projections and scale drawing [6]. In coordinate geometry, the student is expected to recognize the connection between ordered pairs of numbers and locations of points on a plane, that is, emphasis is on the location and relationship of points and figures within the Cartesian plane, while in transformational geometry it is most specifically important to explain how shapes appear as they are moved in space [6]. The authors cannot repeat the considerable evidence pointing to the challenges experienced in teaching coordinate geometry within South African schools, since it was reinstated as part of the Further Education and Training (FET) curriculum in 2012. Such evidence is available in abundance [7-10]. What is lacking in literature however, is how visual-spatial skills influence coordinate geometry content conceptualisation for mathematics pre-service teachers.

Mix contended that variance in mathematics performance is normally explained by the variance in spatial skills among students across all educational levels [11]. This assertion suggests that an individual's spatial skills level can be a yardstick of achievement in mathematics. Literature illustrates that the ability to apply spatial skills in teaching mathematics and the level at which the teachers understand the content are interwoven [1213]. However, despite all these assertions, poor achievement in mathematics among learners has remained unabated worldwide and the failure is normally ascribed to practitioner development [7] [14]. According to the previous, the field of science in mathematics that requires spatial ability most is geometry, but the way teachers give instruction in this field lacks the spatial aspect [15] and hence, students with low spatial skills tend to have problems understanding material provided [16-18]. To enhance learners' spatial skills, teachers must be able to connect the real world with the learners' minds [19]. The purpose of this study was therefore to explore the spatial ability of mathematics PSTs and how this spatial ability affected their ability to solve mathematical problems related to coordinate geometry. The paper thus assessed the behaviour and performance of pre-service teachers (PSTs) showing high and low spatial orientation skills 
as they solved some geometric tasks. This study used a survey and interpretation of responses to coordinate geometry test items to explore the relationship that exists between pre-service teachers' ability to apply spatial skills and their understanding of mathematics content in the context of coordinate geometry. The study addressed the questions: What is the relationship between spatial skills and mathematics performance in mathematics preservice teachers? How do spatial skills impact on the conceptualisation of mathematics content?

In the subsequent sections of this article, the authors provide definitions and discussion of concepts related to spatial-visual skills first. Next, the connections between spatial capabilities, geometrical thinking, and visualization are explored. Finally, the conclusion is reached by discussing spatial skills as core cognitive skills that include spatial visualisation, form perception and visual-spatial working memory.

\subsection{Spatial Visualisation and Spatial Orientation}

Spatial reasoning involves the ability to think and reason by comparing, manipulating, and transforming mental pictures [20]. Seah [21] concurs that spatial reasoning is the capacity to see, inspect and reflect on spatial objects, images, relationships and transformations. Further distinguish spatial skills as comprising spatial visualisation and spatial orientation [20]. Spatial visualisation refers to the ability to visually compare shapes that have changed in position on the plane or in space. This is a very important aspect of conservation of shape for pre-service teachers to realise that the shape stays the same even when it is flipped, reflected, or rotated (recognition of shapes through mental rotation). This is different from spatial orientation which is the ability to look at a fixed figure from several different points of view [20]. Visual spatial skills therefore assist individuals to comprehend spatial relationships between objects and to visualise different scenarios or images [20]. Spatial skills further assist individuals to find their orientation in space through taking in information from the world around them and organising that visual information to create an understanding of meaningful patterns [20]. This is crucial for preservice teachers to master in order to understand coordinate geometry.

Several studies [22-25] examined connections between spatial capabilities (mental rotation and perspective-taking) and geometrical thinking related to symmetry and how visualisation and mental rotation might be related to geometrical figure apprehension (perceptual and operative). Researchers such as [26-29] define spatial skills as core cognitive skills that include spatial visualisation, form perception and visual-spatial working memory. These authors further noted that spatial visualisation refers to learner's ability to imagine and mentally transform spatial information, while form perception is the ability to copy and distinguish shapes from other shapes, including symbols. Visual-spatial working memory enables learners to hold the locations of different objects, landmarks etc, in working memory.

\subsection{What are Visual-Spatial Skills in Mathematics?}

According toprevious study, 'visual-spatial skills' which are used interchangeably with 'visual-spatial abilities' in this study provide us with the ability to visually perceive two or more objects in relation to each other and to one's being [30]. Visual-spatial ability is also defined as the capacity to generate, retain, retrieve and transform visual images [3132]. Consistent with [31]'s definition, [33] opines that visual-spatial skills enshrine the ability to process what one can see in order to comprehend spatial relationships between images. Lohman [31] again avers that spatial ability involves what students do when they visualise shapes in their "mind's eye", hence, spatial ability is the capacity to mentally 
generate, transform and rotate a visual image and this includes the ability to recognise shapes through mental rotation. The integration of these mentally generated images gives rise to visual-spatial thinking [33-34]. The ability to represent a mathematical situation that way may therefore enable learners to organise their thinking in solving a mathematical problem, hence, facilitating conception of ideas [33]. In the same vein, [2,35] aver that spatial skills enable students to mentally manipulate, organise, reason about and make sense of spatial relationships. With spatial skills, a lot of information is mentally represented in spatial format [11,26]. To assist enhancement of spatial skills, most interventions focus on helping students to translate mathematical symbols or problem statements into spatial representations that include number lines, diagrams, concrete models, etc [36]. In another study, [37] reveals that there are two types of thinking processes in mathematics that include the verbal processes and the spatial processes. [37] emphasises that it is the non-verbal visuo-spatial apprehension that supports the deductive processes that is involved in solving geometric problems.

Previous studies have demonstrated a strong correlation between spatial skills and mathematics learning and achievement across all educational levels [2][3][27] [38][39]. In particular, [26] established a strong relationship between spatial skills and success in the many varied strands of mathematics such as geometry, mental arithmetic, calculus, algebra, word problems and more advanced mathematics. [40-43] concur that the spatial ability of a person can affect mathematical ability, and that the spatial ability has a positive relationship with students' ability to solve problems. It is envisaged that spatial skills allow for the perception of visual information, presenting the information internally, then integrate the information with past experiences in order to derive meaning and understanding of mathematical concepts. [37] thus advises that spatial training assists learners to organize situations with mental pictures during problem-solving in mathematics. The frequent use of diagrams, charts and images in showing relationships of mathematical components of a mathematical problem could therefore be a demonstration of spatial skills among learners [37]. This implies that, with spatial ability, individuals learn more easily when presented with visual, diagrammatic or symbolic information in contrast to verbal, auditory or language-based modality [44]. [44] argue that spatial ability involves the capacity to visualise and to graphically represent concepts. Learners with visual-spatial skills hence possess vivid imaginations that enable them to solve mathematical problems. [44]'s view also influences the idea that the ability to represent ideas graphically, the ability to interpret graphs and the ability to manipulate relationships visually indicates visual-spatial skills of learners in mathematics. [44] hence assert that spatial ability is necessary for problem-solving, reasoning and making connections, especially in mathematics.

\subsection{Statement of the problem}

Despite the fact that strong spatial skills are normally associated with success in STEM subjects and that there is convincing evidence that spatial skills are a reliable predictor of mathematics achievement in both high school and university [45-46], questions remain regarding achievement in spatial areas associated with mathematics. Crollen et al. [47] and [16] warn that scaffolding given by teachers sometimes lacks the spatial aspect, and students with low spatial skills tend to grapple with understanding the materials provided. Despite substantial attempts to enhance mathematics achievement among learners, poor performance in mathematics has been consistent the world over. In addition, the majority of studies to date, for example, Wai et al. [48] have however reported correlations between visual spatial skills and mathematics achievement based on primary 
and secondary schools but not university students. To date, no known studies have investigated the association between spatial skills and mathematics in university and the impact of spatial skills on mathematics content knowledge among pre-service teachers. Scant attention has been paid to the mathematics practitioner development regarding preservice teachers' visual-spatial skills to appropriately guide learners in solving mathematical problems. Since literature, for example, [49-50] assert that teachers normally share the same problems as those experienced by their students, it is likely that the teachers' challenges can be inherited by learners. The current study therefore explored pre-service teachers' spatial skills in solving coordinate geometry problems and also examined whether there is a connection between spatial skills and coordinate geometry performance among pre-service teachers.

\subsection{Theoretical Considerations}

Visual-spatial ability is a mental activity [37], hence, this study is informed by [44][51] theory of figural concepts. Fischbein's theory asserts that geometry in general deals with mental entities. The theory describes geometrical figures as having intrinsically conceptual properties. However, the figures are not just mere concepts but visual as well. A geometric figure, according to [51-53] therefore represent mental constructs which concurrently involve both conceptual and figural properties. According to [51], figural concepts reflect spatial properties such as shape, position and quantity/magnitude and at the same time possess conceptual qualities such as ideality, abstractness, generality and perfection. The figural concept is therefore a mental entity that contains figural and conceptual components and is handled by mathematical reasoning in the domain of geometry [51].

According to [53] generating and processing mental images take place within the process of acquisition and use of visual-spatial abilities. Spatial reasoning involves 4 classes of image processing, namely generating an image, inspecting an image to answer questions about it, transforming and operating on an image and maintaining an image in the service of other mental operations, which are all aspects that propel the development of figural concepts [53]. Based on this theory, this study explores the impact of spatial skills in solving coordinate geometry tasks among pre-service teachers.

\section{METHOD}

The entire research procedure is given below in Figure 1.

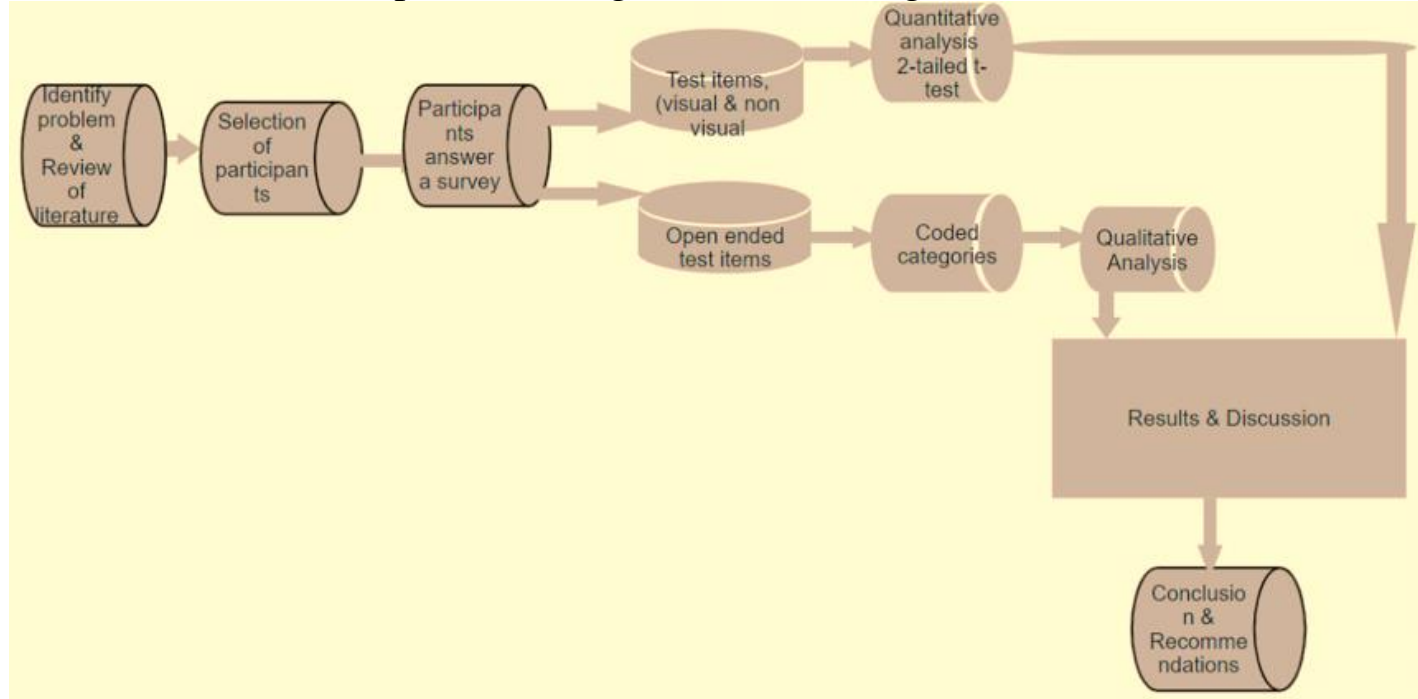

Figure 1. Research Procedures 
This is a mixed methods study where a test was used to collect data from pre-service teacher participants. However, the data was analysed both quantitatively and qualitatively. The participants were secondary school pre-service teachers who had already taken geometry course as part of their training. The forty (40) purposively selected pre-service teachers answered questions on mathematics content, coordinate geometry in particular, that were both non-visual (with written words) and visual using graphical representations with information for the solutions. The non-visual tasks tested the content knowledge whilst the visual tasks tested the spatial knowledge of PSTs. The pre-service teachers answered the questions to ascertain their understanding of the topic and to explore their ability to interpret and analyse visual spatial models to solve mathematical problems in coordinate geometry. The performance of the pre-service teachers in the two sets of data (visual and non-visual) were then compared quantitatively to identify some specific trends in the two performances, in order to establish the relationship between spatial skills and content knowledge. The means and standard deviations for the two sets of data were calculated to facilitate the comparison of the two constructs. The means of the two sets of data were calculated and compared using the paired two tailed $t$-test to find out whether there was a significant difference between them. The means were compared at 5\% level of significance. The result of the $t$-test was followed by a verbal analysis of the outcome [See table 1].

Qualitative data that allowed pre-service teachers to describe their understanding of visual-spatial models was categorised and coded as it is given in Table 1. Some categories that manifested the use of spatial skills were determined from the behaviours observed in the solution of the problems. For ethical reasons, all the names displayed in the presentation and analysis of data are pseudonyms. [44] Posit that the ability to represent ideas graphically (drawing), ability to interpret graphs (showing relations) and the ability to manipulate relationships (correct answers and breaking set) visually indicates visualspatial skills of learners in mathematics [44]. Some categories that manifested the use of spatial skills were therefore identified from overt behaviours observed in the pre-service teacher solutions. The Categories manifesting the use of spatial skills (Adapted from [37]) are shown below.

Table 1. The Categories Manifesting the Use of Spatial Skills

\begin{tabular}{|c|c|c|}
\hline No & Categories & Description \\
\hline 1 & Drawing Relation & $\begin{array}{l}\text { Indicated a marking or drawing with which the pre-service teacher was } \\
\text { attempting to show a mathematical relationship visually rather than just to } \\
\text { keep track of a counting process }\end{array}$ \\
\hline 2 & Correct Answers & $\begin{array}{l}\text { Indicated whether or not the pre-service teachers found the correct answer to } \\
\text { the problem. The ability to interpret the visual spatial models would be } \\
\text { evidence of the existence of spatial skills in the PSTs }\end{array}$ \\
\hline 3 & $\begin{array}{l}\text { Failure/ability to } \\
\text { Break Set }\end{array}$ & $\begin{array}{l}\text { Indicated whether or not the pre-service teachers could demonstrate an ability } \\
\text { to break the problem apart, did not change a mind-set that would provide an } \\
\text { incomplete or inaccurate solution. Since spatial skills require re-seeing or } \\
\text { looking at something in a new way, inflexibility in breaking a mental set could } \\
\text { indicate a lack of spatial skill use }\end{array}$ \\
\hline 4 & Draw Picture & $\begin{array}{l}\text { Indicated the drawing of a diagram, graph, chart etc to provide visual or } \\
\text { spatial relationships. Drawing reflects the skill to plan (spatial-visual skill) } \\
\text { before solving a problem, [54] }\end{array}$ \\
\hline
\end{tabular}

\section{RESULTS AND DISCUSSION}

This study explored pre-service teachers' spatial skills level and how the skills impacted on their performance in mathematics content, coordinate geometry in particular. Quantitative and qualitative analyses were carried out to determine the findings described in the subsequent sections. 


\subsection{Quantitative Analysis of Spatial and Content Knowledge}

Below is a quantitative presentation and analysis of the results for PSTs' performance in the non-visual content of CG and spatial tasks in CG. The quantitative data comprised questions that required PSTs to determine if the given mathematical tasks were true or false.

Table 1 presents a $t$-test analysis of the relationship between the two sets of data in the survey meant to test the PSTs' content and spatial knowledge. The means $\left(\mu_{1}, \mu_{2}\right)$ and standard deviations $(s . d$ ) for content data and spatial data are respectively shown in table 1. The $p$-value for the two sets of data was calculated at 5\% significant level using Excel. The results are shown in Table 1 below.

Table 2. $t$-Test-Testing the Telationship Between Content and Spatial Knowledge

\begin{tabular}{ccc}
\hline & Content Knowledge & Spatial Tasks \\
\hline Mean $\left(\mu_{1,} \mu_{2}\right)$ & $81 \%$ & $85 \%$ \\
s.d & 9.17 & 15.98 \\
$t$-experimental & & 1.1863 \\
p & & 0.2427 \\
\hline
\end{tabular}

$\mathrm{H}_{0}: \mu_{1}=\mu_{2} \quad$ (CK and spatial skills are closely related)

$\mathrm{H}_{1}: \mu_{1} \neq \mu_{2}$ (There is a significant difference between the two constructs)

$\mathrm{P}-$ value $=0.2427>0.05$

The results show that we do not reject $\mathrm{H}_{0}$ but rather conclude that there is sufficient evidence at $95 \%$ confidence interval to claim that PSTs content performance is equal to performance in spatial tasks of CG. This means the two constructs (content and spatial knowledge) are closely related. This close relationship could be ascribed to the fact that PSTs were able to interpret and analyse spatial models with ease, which impacted on and propelled their performance in the content that was non-visual. The result also resonates with those of [12][25] that showed that the ability to apply spatial skills in mathematics teaching is interwoven with the understanding of mathematics content and could be necessary for mathematical reasoning skills. In addition, [13] assert that performance in spatial reasoning tasks was found to correlate with performance in mathematical tasks. To confirm this assertion, the raw marks scored by some PSTs indicated that those with lower marks (below average) in spatial tasks (mean 85\%) scored below average in content (mean $81 \%$ ), for example, R10 had 29\% (below average) in spatial tasks and scored $71 \%$ (below average) in content. R32 had 57\% in spatial tasks and scored $63 \%$ in non-visual-content, all below average. The same applied to R46 who was below average in both spatial tasks and non-visual content.

Generally, the study revealed that the PSTs who scored above average in spatial tasks were also above the average performance in non-visual content except for 3 PSTs only, viz, R20, R35 and R42 which the researchers considered as insignificant. The general performance is a reflection of the interdependence that exists between spatial skills and content knowledge. An analysis of correct and incorrect responses for each question item was also done to ascertain the pre-service teachers' areas of difficulty. Figure 2 below summarises the amount of correct responses on the 23 closed questions that needed a True/False answer. 


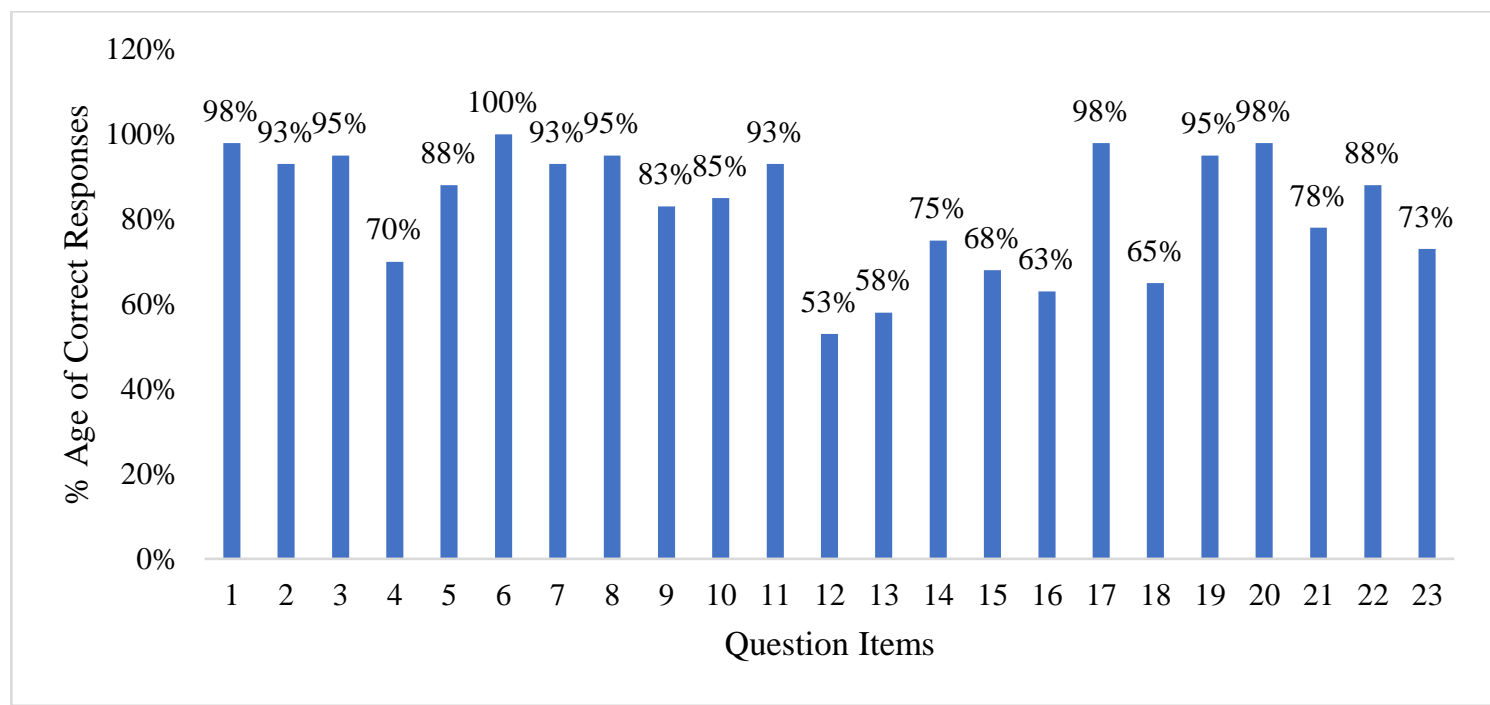

Figure 2. The Number of Correct and Incorrect Responses

In Figure 2, questions such as 1, 6 and 17 received the highest score (over 95\% of the PST got them correct) whilst questions 12, 13, 15, and 16 received the lowest scores. Analysing the questions revealed that PSTs were more successful in tasks that required substitution into a formula or definitions of concepts, than the ones that needed the use of graphs/sketches to solve. For example, for question 1 (98\%), PSTs were required to find the length of the line joining 2 points, in which they used the distance formula $\sqrt{\left(x_{2}-x_{1}\right)^{2}+\left(y_{2}-y_{1}\right)^{2}}$ to find the answer. Although [32] allude that processes of spatial thinking may include low levels of thinking, such as recognizing, defining, and listing, [29] foregrounded that spatial thinking should enshrine advanced thinking of a spatial nature, based on expert knowledge. It is possible that pre-service teachers could just use the formula that they internalised before, without clear conception of the formula, and this conflicts [44]'s definition of spatial ability. On the other hand, question 12 required PSTs to determine whether $y=m x+m d$ is the equation of a line with gradient $m$ and intercept $d$ on the $x$ axis. The PSTs performance was quite low on this task (53\%), implying that $47 \%$ of the PSTs could not get the answer correct. According to [33] the ability to represent a mathematical situation in the mind's eye enables learners to organize their thinking in solving a mathematical problem, hence facilitating conception of ideas. The fact that most students struggled to answer this question was a signal of a deficit in spatial awareness because they could not make sense of spatial relationships [2,35]. The authors believe that the PSTs could have re-written the question in form of a Cartesian graph in order to demonstrate their conceptual understanding of the gradient of a line. The inability to demonstrate the relationship between the graph and the equation was enough evidence of thin spatial ability among students. According to [36], spatial skills should enable students to translate mathematical symbols/equations into spatial representations that include graphs. Some PSTs, for example, R3 and R26, sketched the line graph as part of their working and got the answer correct. This result indicates that the graphs drawn had considerable impact on R3 and R26's successful identification of the gradient of the line. Failure to answer this question was further indicative of the fact that PSTs' visual-spatial abilities were generally low as concurred by [44] who argued that spatial ability involves the capacity to visualise and to graphically represent concepts in mathematics. Drawing upon the theory of figural concept, [53] explain that generating and processing mental images take place within the process of using visual-spatial abilities. The researchers 
believe that the graph therefore played an important role in some of the PSTs reasoning on this question.

\subsection{Qualitative Analysis of Spatial and Content Knowledge}

Below are example questions adapted from the survey to give information about the PST's spatial orientation skills.

Table 3. Example Questions about the PST's Spatial Orientation Skills

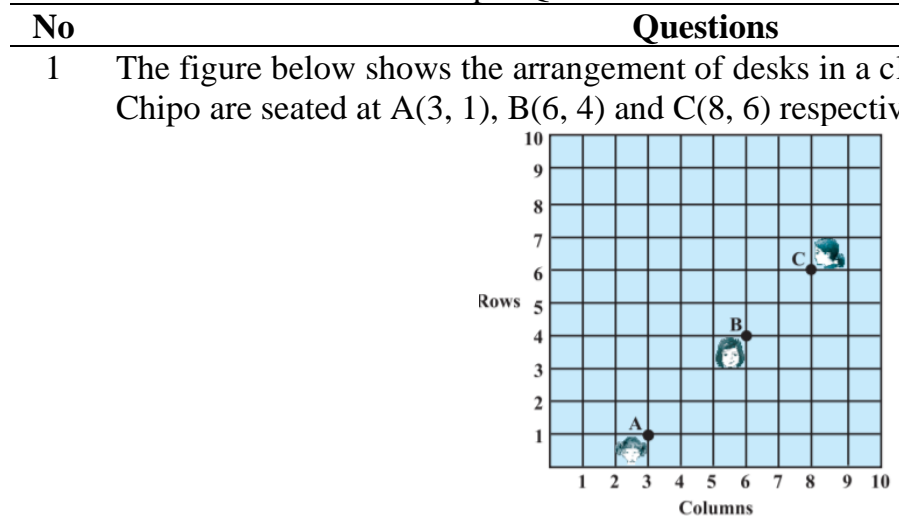

Do you think Assa, Bernard and Chipo are seated in a line? Give reasons for your answer.

2 In a classroom, 4 friends are seated at the points $\mathrm{A}, \mathrm{B}, \mathrm{C}$ and $\mathrm{D}$ as shown in figure below.

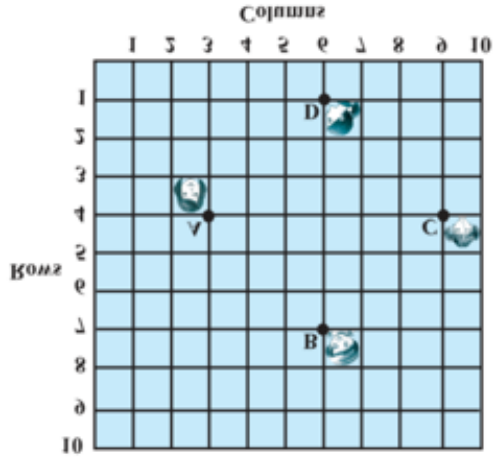

Linda and Charles walk into the class and after observing for a few minutes Linda asks Charles, "Don't you think ABCD is a square?" Charles disagrees. Find which of them is correct and why?

3 Study the graph below and find out whether the two lines $y=x-1$ and $3 x+4 y=24$ are perpendicular.

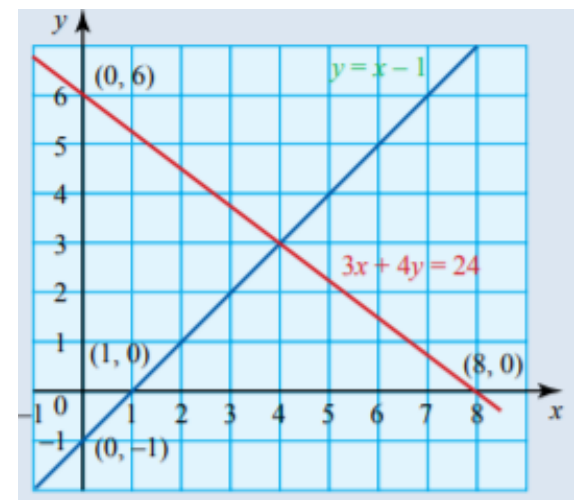

4 Show whether figure below represent the same general equation $\frac{x}{a}+\frac{y}{b}=1$, where $a$ is the $\mathrm{x}$-intercept and $b$ is the $\mathrm{y}$-intercept. 


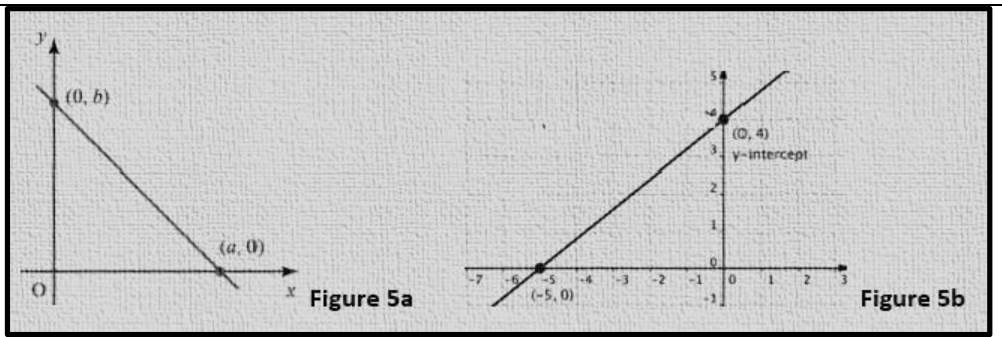

5 Figure below shows the supply and demand of labour for a particular industry in relation to the wage paid per hour. Supply is the number of people willing to work for a particular wage, and this increases as the wage paid increases. Demand is the number of workers that employers are prepared to employ at a particular wage: this is greatest for low wages.

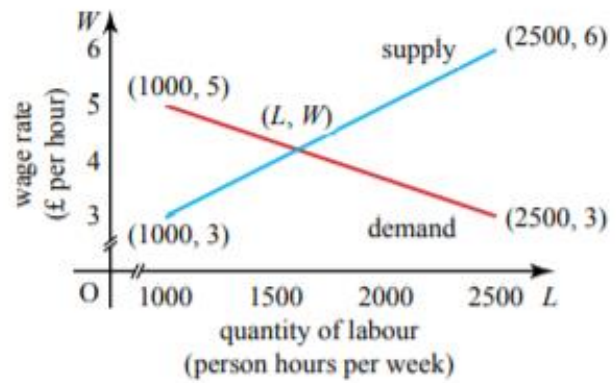

- In figure above, show all the necessary steps to find the equations representing the two lines.

- In figure above, giving reasons, estimate the values of $\mathrm{L}$ and $\mathrm{W}$ at which the market 'clears', i.e. at which supply equals demand

6 Figure below shows the curves $y=x^{2}-4 x+1$ and $y=7-x^{2}$.

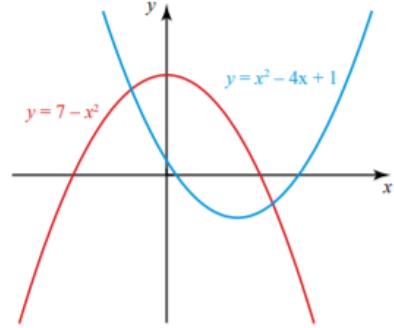

- In figure above, giving reasons, find the coordinates of the turning points of the two curves

- In figure above, state whether the turning points in Figure 7 are minimum or maximum points on each of the curves. Justify your answer.

In this study, some categories that manifested the use of spatial skills were identified from the conspicuous trends observed in the PSTs solutions as it is explained in Table 1.

\subsubsection{Draw Relation}

It was a tall order for most PSTs to form relations between concepts. For example, on item 27, figures $5 \mathrm{a}$ and $5 \mathrm{~b}$ show two different visual representations of the same equation $\frac{x}{a}+\frac{y}{b}=1$. PSTs were expected to use visualisation skills and knowledge of symbolic language to explain the concept represented by the 2 graphs. The question tested PSTs understanding of graphical representation, that is, the ability to recognise that a line can be represented in different forms, thus, externally expressing mental visual model (line graph) in a different format (equation). A significant number of PSTs $(62,1 \%)$ had challenges demonstrating the relationship that bound the two-line graphs [Figure 5]. This was an illustration of a lack of the skill to process what one could see in order to understand 
and visualise the spatial relationship between the 2 graphs. Taking heed of [20]'s idea, spatial skills should assist students to understand spatial relationships between images and help them to visualise various scenarios. [31] concurred that spatial skills afford learners the ability to transform visual images. So, failure to establish the relationship between the two graphs and the line $\frac{x}{a}+\frac{y}{b}=1$ resembled a lack of spatial skills in the PSTs.

In addition, not all participants could visualise that the 4 points on the plane formed a square on item 25 . Although a bigger number were agreeable that the objects formed a square, the reasons provided were not quite satisfactory. The PSTs concluded that the figure was a square by just looking at the 4 equal sides displayed on the plane. For example, R4's response was as follows.

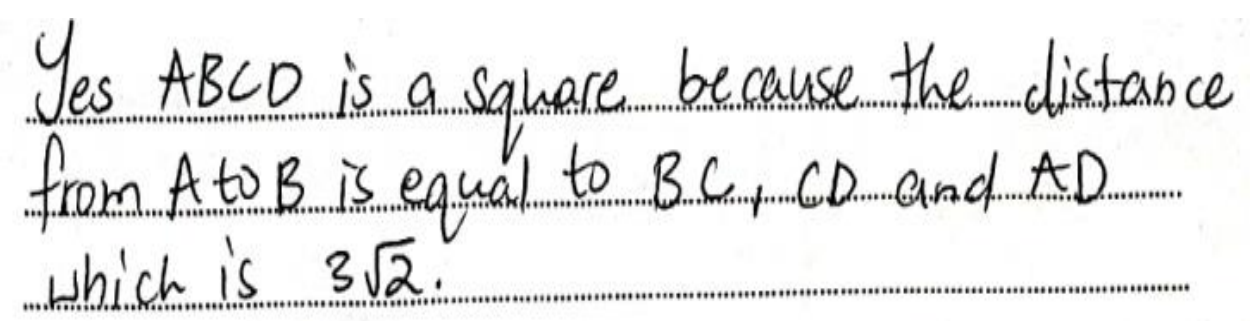

Figure 3. PST R4's Response to Item 25

Participants tended to imagine of a square with 4 equal sides and not the ideal perfect mathematical square which is the object of mathematical reasoning and includes the representation of spatial properties [51]. The figure was not just a quadrilateral with 4 equal sides but also had equal angles which were right angles and had equal diagonals. Their responses suggested a lack of concept definition of a square. The results showed that $82.1 \%$ against $17.9 \%$ of the PSTs had challenges proving that the image was a square. According to [51], the properties of a geometric figure are derived from definitions in certain axiomatic systems. This implies that the square in the question had a conceptual nature controlled by its definition, which the participants failed to realise. In observing the image, the participants failed to show a thorough understanding of the concept of a square. Unless participants understand that the image has intrinsically conceptual properties, they would solve the problem based on what they see only (visual component) yet images and concepts interact intimately [51]. [51] affirms that most people act as if no other quality counts while operating with a geometrical figure and this exhibits lack of real conceptual understanding of the figure. The participants' inability to prove the square could therefore be an indication that the figural and conceptual systems have not yet blended in germane figural concepts, and this reflects visuo-spatial skills deficiency [51]. [52] also stressed the interaction between a geometrical figure and a geometrical concept, but asserts that, from the students' perspectives, there can be a tension between the two.

\subsubsection{Correct Answer}

Visuo-spatial skills have been found to predict mathematical achievement [26][45] [48] and getting the correct answer without a hint or assistance is a manifestation of spatial skills in a learner [37]. A significant number of PSTs had correct answers that they obtained without a hint from most of the tasks in the test. However, the answers were presented in various forms. Some were verbally described while some were solved with the aid of images. As for the questions that had images, the interpretation differed. For example, in item 24, spatial orientation skill appeared to be indicated in several ways where geometric content was involved. After being asked to find out whether the 3 objects given on a 
Cartesian plane were in a straight line, several PSTs exhibited the skill of ascertaining ideas through observation of images and ability to determine their position in relation to each other. This was an exhibition of spatial skills in the PSTs according to [30] who contends that visual-spatial skills provide learners with the ability to perceive two or more objects in relation to each other. On the same item 24, a quarter of PSTs (25\%) used a ruler to join the 3 objects, which was however a lower level spatial skill of finding the answer. [32] contends that processes of spatial thinking may include low levels of thinking, such as recognizing, defining, and listing. R1 is an example of the PSTs who responded this way:
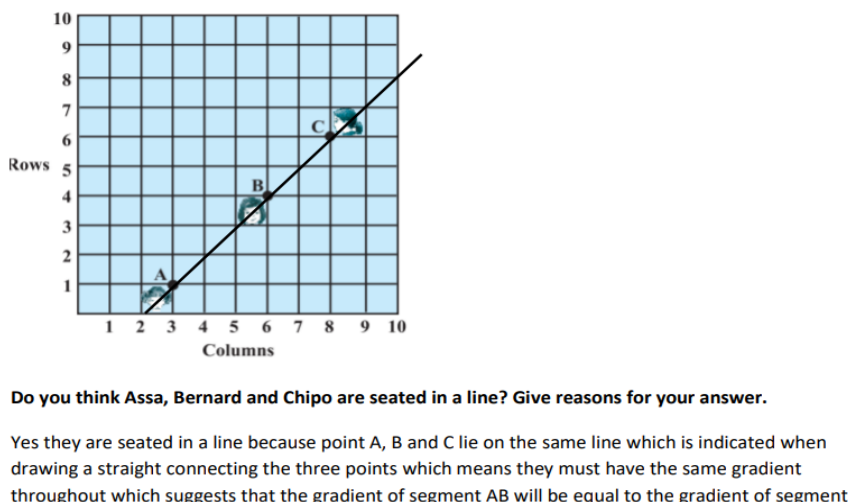
drawing a straight connecting the three points which means they must have the same gradient

Figure 4. PST R1's Response to Item 24

Other PSTs (35\%) used algebraic principles of finding the gradients of $\mathrm{AB}, \mathrm{BC}$, and $\mathrm{AC}$ which were all equal to 1 . A few PSTs (10\%) made use of distances of segments where they showed that distances $\mathrm{AB}+\mathrm{BC}=\mathrm{AC}$. For example R18 wrote:

$$
\begin{aligned}
& A B=\sqrt{(6-3)^{2}+(4-1)^{2}}=3 \sqrt{2} \\
& A C=\sqrt{(8-3)^{2}+(6-1)^{2}}=5 \sqrt{2} \\
& B C=\sqrt{(8-6)^{2}+(6-4)^{2}}=2 \sqrt{2} \\
& \therefore A C=A B+B C \\
& \text { HENCE POINTS A, B AND C ARE COLLINEAR }
\end{aligned}
$$

Figure 5. PST R18's Response to Item 24

A slightly fewer (7.5\%) calculated the equation of $\mathrm{AB}$ and substituted point $\mathrm{C}$ to ascertain whether $\mathrm{C}$ satisfied the equation for line AB. A total of $77.5 \%$ PSTs therefore got the correct answers on item 24 with the aid of the image. They were able to interpret the image, and solved the problem in various ways and this portrayed some level of visual spatial skills according to [21] who concurs that spatial ability is the capacity to see, inspect and reflect on spatial objects, images, relationships and transformations. However, $22.5 \%$ of the PSTs tried to answer the same question by verbally describing the solution and got the wrong answers. For example, R7 explained that the 3 objects were in a straight line "because A, B, C form a straight line when joined together." R46 also wrote, "Yes, because they are collinear and they are all on the same quadrant." The different ways with which the PSTs responded to item 24 confirm the results of the study by [37] that there are two groups of PSTs mathematics students, namely the low and high spatial orientation groups. The current study revealed that the low spatial group, that is, those that attempted to solve the problem by verbally describing the solutions got the answers wrong. The PSTs R7 and R46 hence portrayed a deficiency of spatial skills on this question. Their performance 
concurs with [37] who explains that any attempt to verbalise the process involved in spatial thinking ceases to be spatial thinking. [37] emphasised that it is the non-verbal visuospatial apprehension that supports the deductive processes that is involved in solving geometric problems. The participants (R7 \& R46)'s interpretation of the images was incorrect and they did not have adequate figural concept for the line. With reference to item 26, some PSTs, by a mere look at the graph, they concluded that the two lines were perpendicular to each other, which was not correct. For example, R17 wrote: "They are perpendicular because the two lines slopes are negative reciprocals of each other, they also form right angles."

Though the graph was an image and a spatial representation, its properties were imposed by an abstract definition where the product of the two gradients, after calculating algebraically, should be a negative one for the two lines to be perpendicular. [51] advises that PSTs ought to be trained to follow carefully the requirements of the definition, sometimes in apparent contradiction to the suggestions of the figure, which is a reflection of visual-spatial skills.

\subsubsection{Failure to break set}

This study showed that the PSTs who attempted to answer some questions using verbal descriptions (low spatial orientation group) had challenges in solving some tasks and the same participants also dominantly failed to break set for geometric problems. In items 32 and 33 (Figure 7), participants had various ways of interpreting the models (graphs). In these tasks, PSTs were required to find the coordinates of the turning points and to determine whether the points were maximum or minimum respectively. The participants used various approaches to interpret the sketches to find the coordinates of the turning points and determine their status ( $\mathrm{max} / \mathrm{min})$. Slightly less than a quarter $(22.5 \%)$ used the principle of calculus (differentiation in relation to gradient, e.g. $\frac{d}{d x}\left(x^{2}-4 x+\right.$ $1=0)$ ) to determine the turning points. Very few $(5 \%)$ used the method of completing the square to find the turning points, for example, if:

$y=x^{2}-4 x+1$

$\Rightarrow y=(x-2)^{2}-3$. Therefore, $y$ can be only minimum when $(x-2)=0 . \Rightarrow x=2$ for $\mathrm{y}=-3$. Hence the minimum point is $(2,-3)$.

A quarter $25 \%$ used the concept that a quadratic graph turns at a point where $\mathrm{x}=$ $\frac{-b}{2 a}$ from the general quadratic equation $a x^{2}+b x+c=0$. R24 presented her answer as follows:

32. In figure 6 above, state the coordinates of the turning points of the two curves

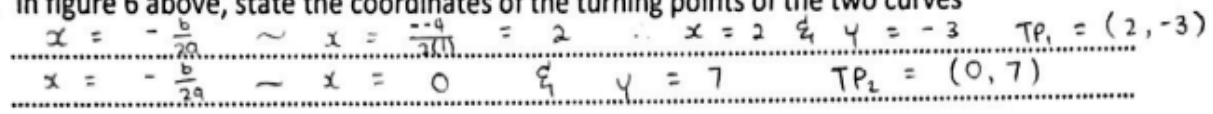

Figure 6. PST R24's Response to Item 32

However, it was rather difficult to tell whether the PSTs understood how $\mathrm{x}=\frac{-b}{2 a}$ was developed or it was mere memorisation of concepts because most of them could not justify their responses. No explanation was given regarding the development of $\mathrm{x}=\frac{-b}{2 a}$ to show conceptualisation of the quadratic graph. Whilst most PSTs could recite $\mathrm{x}=\frac{-b}{2 a}$ as an expression for finding the turning points of a parabola, only a few seemed not to understand it as the outcome of completing the square of a quadratic expression. This is a confirmation 
of [21]'s study which pointed out that geometry learning today is characterised by memorising the vocabulary and application of formulae in routine calculations. Slightly more than half of the PST $(52.5 \%$, that is, $22.5+5+25 \%)$ demonstrated the ability to describe the 3 models. This ability to interpret visual models and determine algebraically the concept of the turning point in relation to the given sketches is a reflection of the presence of spatial skills in the learners [44]. [44]'s view shows that the ability to represent ideas graphically, the ability to interpret graphs and the ability to manipulate relationships visually indicates visual-spatial skills of learners in mathematics. However, $47.5 \%$ were not flexible enough to use any one of the models alluded to above to come up with the corrects answer. Failure to re-visualise the graph in a different format and use the format to develop the concept $\mathrm{x}=\frac{-b}{2 a}$ was a reflection of a lack of spatial skills to solve the problem in the PSTs because students with low spatial skills tend to have problems understanding material provided [16][17 [18].

In addition, although a significant number of participants got correct answers, PSTs like R22 and R29 showed that their estimate level was low as reflected by the way they responded to item 32. Taking heed of [47] study which found that learners with poor visuospatial skills have less accurate estimation performance than those with good visuo-spatial skills, the low estimate level of the PSTs resonates with low visual spatial skills. In this question, the visual apprehension of the appropriate points of the figures were tested. R22 and R29 could not even estimate to link their answers to the positions of the graphs on the plane. For example, on the graph, the turning point of $y=7-x^{2}$ is on the positive side of the $y$-axis but R22 is showing this as negative $(1 ;-2)$ :

For $y=x^{2}-4 x+1 \quad$ For $y=1-x^{2}$
TP
$(0,1) \quad$ TP $(1,-2)$

Figure 7. PST R22's Response to Item 32

Similarly, R29 is showing the turning point of $y=x^{2}-4 x+1$ as $(4 ; 1)$, as it is shown below:

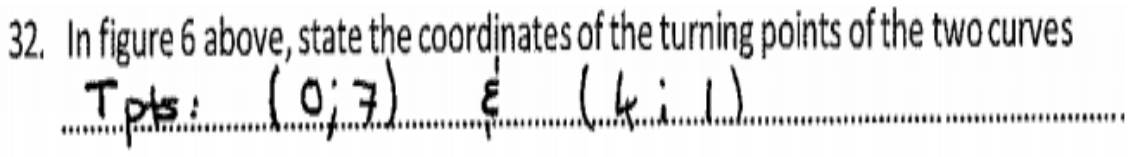

Figure 8 PST R29's Response to Item 32

However, the position of the turning point is on the negative $y$-axis. The PSTs could not therefore change their mental set that provided an incorrect/inappropriate solution. According to [37], this is indicative of a lack of spatial skills in the PSTs, because individuals with spatial skills should be able to interpret visual spatial models/graphs.

\subsubsection{Draw picture}

Drawing is considered as a means of planning and assembling ideas together [54] in the process of solving mathematical problems. Furthermore, drawing and spatial abilities share common conceptual ground and are dependent upon spatial abilities [55]. The ability to make sketches/graphs/charts before answering a problem was considered as a spatial skill among the PSTs in this study. However, only a few PSTs could draw some lines to provide visual spatial relationships to solve some tasks in the test. Although there were few questions in the test that needed drawing, for example item 29, most PSTs had challenges solving the problems. Item 29 required the PSTs to estimate the values of 
supply (L) and demand (W) at which the market clears. The graph was given but most PSTs calculated and equated the equations of $\mathrm{L}$ and $\mathrm{W}$ in order to find the point of intersection. Whilst this was an acceptable method to find the values of $\mathrm{L}$ and $\mathrm{W}$ at which the market clears, there were very few PSTs who got the correct answer because, in the process, they committed several computational errors. The algebraic principles they tried to apply failed them. Instead of using the graph to draw horizontal and vertical lines from the point of intersection to the axes to estimate the solution, most of them were not flexible enough to use this method which the authors thought was going to be an indication of spatial orientation skills in the PSTs. This decision was influenced by [37] who posits that the ability to add marks (to a graph) to show mathematical relationships portrays the spatial orientation skills in a learner. Among the 40 participants who answered this question, not even a single participant drew the lines to obtain the solution. [37] contends that high spatial orientation individuals are therefore better able to estimate the approximate magnitude of the answer than the verbal orientation ones. Failure to draw the lines was therefore indicative of low spatial orientation skills. Spatial orientation skills assist individuals to find their orientation in space through making use of available information and organising that visual information to create an understanding of meaningful patterns [20].

\section{CONCLUSION}

This study explored the relationship between PSTs visual-spatial orientation skills and their content knowledge in coordinate geometry. The results of the study demonstrated that the PSTs' spatial skills were related to their content knowledge in coordinate geometry as reflected by the quantitative analysis of the study in Table 2 . The study also established that there were some PSTs who employed more verbal descriptions of the relevant information in a problem than others (See section 3.2.2). Generally, the PSTs who displayed high spatial visualisation skills are the ones who scored most of the answers correctly. This is evidence that the PSTs operated at different levels of spatial ability. In light of this, [37] talks about low and high spatial visualisation skills as well as low and high verbal skills in solving mathematics problems.

The findings also indicate that only a few PSTs demonstrated adequate figural concept knowledge relating to coordinate geometry. Some PSTs could hardly identify or find the turning points appertaining to the prototypical image of the graph in Figure 7 because they focused more on algebraic calculations excluding the figural component of the image/model, for example, R22 and R29. [53] aver that spatial reasoning involves generating an image and inspecting the image to answer questions about it. [37] explains that spatial skills enable the subject to make sense out of visual information. Based on these results, the authors concluded that the conceptual and figural aspects were not harmonised in most of the questions, which could be a visual-spatial reasoning deficiency among PSTs.

The study recommends that it is necessary for PSTs to focus on the figural concept aspect of a task in coordinate geometry to demonstrate spatial skills in solving mathematical problems appertaining to geometry. It is also essential that PSTs are acquainted with such skills (figural concepts) because teaching for spatial reasoning requires teachers to have conceptual understanding of properties of figures, their position in the space, their connectedness between them in the formation of theorems and the learning of other mathematical concepts [21]. 


\section{REFERENCES}

[1] P.J. Kok, "The Relationship Between Pre-service Teachers' Spatial Experience and Spatial Visualisation at a Rural-based University," African Journal of Research in Mathematics, Science and Technology Education, vol. 25, no. 1, pp. 103-111, 2021. https://doi.org/10.1080/18117295.2021.1923884

[2] K. Atit, J. R. Power, N. Veurink, D.H. Uttal, S. Sorby, G. Panther, C. Msall, L. Fiorella and M. Carr, "Examining the role of spatial skills and mathematics motivation on middle school mathematics achievement," International Journal of STEM Education, vol. 07, no. 38, pp. 1-13, 2020. https://doi.org/10.1186/s40594020-00234-3.

[3] K.S. Mix, S.C. Levine, Y.L. Cheng, C.J. Young, D.Z. Hambrick and S. Konstantopoulos, "The latent structure of spatial skills and mathematics: Further evidence from wave 2," Journal of Cognition and Development, vol. 04, pp. 465-492, 2017. https://doi.org/10.1037/xge0000182

[4] National Research Council, "Learning to think spatially: GIS as a support system in the K-12 curriculum", National Academies Press, Washington DC, 2006.

[5] J. Buckley, N. Seery, D. Canty, "A Heuristic Framework of Spatial Ability: a Review and Synthesis of Spatial Factor Literature to Support its Translation into STEM Education”, Educational Psychology Review, vol. 30, pp. 947-972, 2018. https://doi.org/10.1007/s10648-018-9432-z

[6] D. Abrahamson, M.J. Nathan, C. Williams-Pierce, C. Walkington, E.R. Ottmar, H. Soto and M.W. Alibali, "The Future of Embodied Design for Mathematics Teaching and Learning", Frontiers in Education, vol. 5, no. 147, 2020. https://doi.org/10.3389/feduc.2020.00147

[7] K. Jones, "Issues in the teaching and learning of geometry", In L. Haggarty (Ed.), Aspects of Teaching Secondary School Mathematics: Perspectives on Practice, pp. 121-139, 2002. London: Routledge Falmer. https://doi.org/10.1002/t1.62.

[8] S.A. Tachie, "The challenges of south african teachers in teaching euclidean geometry," International Journal of Learning, Teaching and Educational Research, vol. 19, no. 8, pp. 297-312, 2020.

https://doi.org/10.26803/ijlter.19.8.16.

[9] K. Luneta, "Foundation Phase Teachers' (Limited) Knowledge of Geometry," South African Journal of Childhood Education, vol. 4, no. 3, pp. 71-86, 2014. https://doi.org/10.4102/sajce.v4i3.228

[10] T. Adolphus, "Problems of Teaching and Learning of Geometry in Secondary Schools in Rivers State, Nigeria," International Journal of Emerging. Sciences, vol. 1, no. 2, pp. 143-152, 2011.

[11] K.S. Mix, "Why Are Spatial Skill and Mathematics Related?" Child Development Perspectives, vol. 13, no. 2, pp. 121-126, 2019. https://doi.org/10.1111/cdep.12323.

[12] M.G. Tosto, K.B. Hanscombe, C.M.A. Haworth, O.S.P. Davis, S.A. Petrill, P.S. Dale, Y. Kovas, "Why do spatial abilities predict mathematical performance?" Developmental Science, vol. 17, no. 3, pp. 462-470, 2014. https://doi.org/10.1111/desc. 12138

[13] C.J. Young, S.C. Levine and K.S. Mix, "The Connection Between Spatial and Mathematical Ability Across Development", Frontiers in Psychology, vol. 9, no. 755, 2018. https://doi.org/10.3389/fpsyg.2018.00755.

[14] B. Jaworski, "Theory and practice in mathematics teaching development: Critical inquiry as a mode of learning in teaching," Journal of Mathematics Teacher Education, vol. 09, no. 2, pp. 187-211, 2006. 
[15] R.O.E. Putri, "Spatial Skill Profile of Mathematics Pre-Service Teachers", Journal of Physics: Conference Series, vol. 947, no. 1, https://doi.org/10.1088/17426596/947/1/012065.

[16] A. Bakker, J. Smit, and R. Wegerif, "Scaffolding and dialogic teaching in mathematics education: Introduction and review," ZDM Mathematics Education, vol. 47, pp. 1047, 2015.

[17] M.T. Battista, "Spatial visualization and gender differences in high school geometry", Journal for research in mathematics education, vol. 21, no. 1, pp. 4760, 1990.

[18] D.H. Clements, "Geometric and Spatial Thinking in Young Children" Opinion paper National Science Foundation, 1998.

[19] S.A. Sorby, "Developing 3-D spatial visualization skills", Engineering Design Graphics Journal, vol. 63, no. 2, 2009.

[20] D.L. Bahr, and L.A. DeGarcia, "Elementary mathematics is anything but elementary", Wadsworth, Cengage Learning, USA, 2010.

[21] R. Seah, "Understanding Geometric Ideas: Pre-service Primary Teachers' Knowledge as a Basis for Teaching," Proceedings of the 38th annual conference of the Mathematics Education Research Group of Australasia, pp. 571-578, 2015. Sunshine Coast: MERGA

[22] X. Xistouri and D. Pitta-Pantazi, "Spatial rotation and perspective taking abilities in relation to performance in reflective symmetry tasks," in Proceedings of the 30th Conference of the International Group for the Psychology of Mathematics Education, pp. 425-432, 2006.

[23] P. Kalogirou, I. Elia, and A. Gagatsis, "Spatial Ability and Geometrical Figure Understanding," In Gagatsis, A., Kuzniak, A., Deliyianni, E., \& Vivier, L. (Eds), Cyprus and France Research in Mathematics Education, pp. 105-118, 2009. Lefkosia: University of Cyprus.

[24] R. Duval, "Representation, Vision and Visualization: Cognitive Functions in Mathematical Thinking. Basic Issues for learning", Retrieved from ERIC ED 466 379, 1999.

25] K. Jones and M. Tzekaki, "Research on the teaching and learning of geometry. In A. Gutiérrez, G. Leder \& P. Boero (Eds.)," The Second Handbook of Research on the Psychology of Mathematics Education: The Journey Continues. pp. 109-149. Rotterdam: Sense, 2016.

[26] K.S. Mix, Y.L. Cheng, "The relation between space and math: developmental and educational implications," Advances in Child Development Behavior, 42, New York, NY, Elsevier, 2012.

[27] K.S. Mix, S.C. Levine, Y.L. Cheng, C. Young, D.Z. Hambrick, R. Ping, et al, "Separate but correlated: the latent structure of space and mathematics across development," Journal of Experimental Psychology: General, vol. 145, no. 9, pp. 1206-1227, 2016. https://doi.org/10.1037/xge0000182

[28] D.H. Uttal, N.G. Meadow, E. Tipton, L.L. Hand, A.R. Alden, C. Warren and N.S. Newcombe, "The malleability of spatial skills: A meta-analysis of training studies," Psychological Bulletin, vol. 139, no. 2, pp. 352-402, 2013. https://doi.org/10.1037/a0028446

[29] T. Ishikawa, N.S. Newcombe, "Why spatial is special in education, learning, and everyday activities", Cognitive Research: Principles and Implications, vol. 6, no. 20, 2021. https://doi.org/10.1186/s41235-021-00274-5. 
[30] B. Rittle-Johnson, E.L. Zippert and K.L. Boice, "The roles of patterning and spatial skills in early mathematics development," Early Childhood Research Quarterly, vol. 46, no. 1, pp. 166-178, 2019. https://doi.org/10.1016/j.ecresq.2018.03.006.

[31] D.F. Lohman, "Spatial ability", pp. 97-116, Hillsdale, NJ, Erlbaum, 1996.

[32] S. Metoyer, S.W. Bednarz, R.S. Bednarz, "Spatial thinking in education: Concepts, development, and assessment”, A \& M University, Texas, 2015. https://doi.org/10.1007/978-4-431-55519-3_3.

[33] L.E. Mnguni, "The theoretical cognitive process of visualization for science education," Springer Plus, vol. 3, Article no. 184, 2014. https://doi.org/10.1186/2193-1801-3-184.

[34] R.E. Mayer, "Learning and instruction", Prentice-Hall, Upper Saddle River, NJ, 2003.

[35] N.S. Newcombe, and T.F. Shipley, "Thinking about spatial thinking: New typology, new assessments", pp. 179-192, Springer, Dordrech, 2015. https://doi.org/10.1007/978-94-017-9297-4-10.

[36] D.H. Uttal, K.V. Scudder and J.S. DeLoache, "Manipulatives as symbols: A new perspective on the use of concrete objects to teach mathematics" Journal of Applied Developmental Psychology, vol. 18, no. 1, pp. 37-54, 1997. https://doi.org/10.1016/S0193-3973(97)90013-7

[37] L.A. Tartre, "Spatial Orientation Skill and Mathematical Problem Solving," Journal for Research in Mathematics Education, vol. 21, no. 3, pp. 216-229, 1990.

[38] M.B. Casey, R.L. Nuttall, and E. Pezaris, "Spatial-mechanical reasoning skills versus mathematics self-confidence as mediators of gender differences on mathematics subtests using cross-national gender-based items", Journal for Research in Mathematics Education, vol. 32, no. 1, pp. 28-57, 2001. https://doi.org/10.2307/ 749620.

[39] B.N. Verdine, R.M. Golinkoff, K. Hirsch-Pasek and N.S. Newcombe, "Links between spatial and mathematical skills across the preschool years," Monographs of the Society for Research in Child Development, vol. 82, no. 1, pp. 1-150, 2017.

[40] M. Turğut and Y. Süha, "Relationships Among Preservice Primary Mathematics Teachers' Gender, Academic Success and Spatial Ability,” International Journal of Instruction, vol. 5, no. 2, 2012.

[41] B. Rabab'h and V. Arsaythamby, "Spatial Visualization as Mediating between Mathematics Learning Strategy and Mathematics Achievement among 8th Grade Students," International Education Studies, vol. 85, 2015. https://doi.org/10.5539/ies.v8n5p1

[42] B.N. Verdine, R.M. Golinkoff, K. Hirsh-Pasek, N.S. Newcombe, A.T. Filipowicz, A. Chang, "Deconstructing Building Blocks: Preschoolers' Spatial Assembly Performance Relates to Early Mathematical Skills," Child Development journal, vol. 85, no. 3, pp. 1062-1076, 2014. https://doi.org/10.1111/cdev.12165.

[43] R.D. Hannafin, M.P. Truxaw, J.R. Vermillion and Y. Liu, "Effects of Spatial Ability and Instructional Program on Geometry Achievement," The Journal of Educational Research, vol. 101, no. 3, pp. 148-157, 2010. https://doi.org/10.3200/JOER.101.3.

[44] R. Udhaya Mohan Babu and G. Kalaiyarasan, "Visual-Spatial intelligence-A Best creativity Agency," Conference: Health indicator for physical and cognitive fitness education, 2016. 
[45] A.G. Carlson, E. Rowe, T.W. Curby, "Disentangling fine motor skills' relations to academic achievement: the relative contributions of visual-spatial integration and visual-motor coordination," Journal of Genetic Psychology, vol. 174, no. 5-6, pp. 514-533, 2013. https://doi.org/10.1080/00221325.2012.717122.

[46] K.A. Gilligan, E. Flouri and E.K. Farran, "The contribution of spatial ability to mathematics achievement in middle childhood," Journal of Experimental Child Psychology, vol. 163, no. 2017, pp. 107-125, 2017. https://doi.org/10.1016/j.jecp.2017.04.016

[47] V. Crollen, C. Vanderclausen, F. Allaire, A. Pollaris, M. Noël, "Spatial and numerical processing in children with non-verbal learning disabilities," Research in Developmental Disabilities, vol. 47, pp. 61-72, 2015. https://doi.org/10.1016/j.ridd.2015.08.013

[48] J. Wai, D. Lubinski, and C.P. Benbow, "Spatial Ability for STEM Domains: Aligning Over 50 Years of Cumulative Psychological Knowledge Solidifies Its Importance," Journal of Educational Psychology, vol. 101, no. 4, pp. 817-835, 2009. https://doi.org/10.1037/a0016127

[49] S. Wang and M. Kinzel, "How do they know it is a parallelogram? Analysing geometric discourse at van Hield level 3," Research in Mathematics Education, 2014. https://doi.org/10.1080/14794802.2014.933711

[50] D.A. Stylianou, "Teachers' conceptions of representation in middle school mathematics," Journal of mathematics Teacher education, vol. 13, pp. 325-343, 2010. https://doi.org/10.1007/s10857-010-9143-y.

[51] E. Fischbein, "The Theory of Figural Concepts," Educational Studies in Mathematics, vol. 24, no. 2, pp. 139-162, 1993.

http://www.jstor.org/stable/3482943

[52] M.A. Mariotti, "The Interaction Between Images and Concepts in Geometrical Reasoning,", Doctoral thesis, Tel Aviv University, 1995.

[53] E. Miragliotta, and A. Baccaglini-Frank, Visuo-spatial abilities and geometry: A first proposal of a theoretical framework for interpreting processes of visualization, Dublin, ffhal-01950545, 2017.

[54] H. Caldwell, and B. Moore, "The art of writing: Drawing as preparation for narrative writing in the primary grades," Studies in Art Education, vol. 32, no. 4, pp. 207-219, 1991. https://doi.org/10.2307/1320873.

[55] Li-Ming Liu, "The Relationships between Creativity, Drawing Ability, and Visual/ Spatial Intelligence: A Study of Taiwan's Third-Grade Children," Asia Pacific Education Review, vol. 8, no. 3, pp. 343-352, 2007. 